\title{
Improvement of Rainwater Infiltration Property and Its Effect on the Corresponding Storage Capacity of Soil in Urban Green Space
}

\author{
LOU Keke1, WU Zhengguang ${ }^{1 *}$, LU Zhiping ${ }^{1}$, KANG Aihong,YIN Chengsheng ${ }^{2}$, XU Xueling ${ }^{1 a}$ \\ ${ }^{1}$ College of Civil Science and Engineering, Yangzhou University, Yangzhou, Jiangsu 225127, China \\ 2.Yangzhou Highway Management Office of Jiangsu Province, Yangzhou, Jiangsu 225002, China
}

\begin{abstract}
Urban green space whose soil permeability is the main factor affecting hydrological cycle plays a very important role in promoting rainwater infiltration, replenishing groundwater and reducing peak flow. In order to enhance the storage and infiltration ability of soil, different types and contents of conditioner are added to study the laws of the changes in permeability of various soils. The results showed that straw and sawdust can effectively increase the permeability coefficient of soil. According to the comparison under the same conditions, the improvement effects of straw is slightly better than sawdust, but no order of magnitude difference. The sandy soil reformed by $3.6 \%$ Straw or $4.2 \%$ Sawdust and the loam reformed by $29.5 \%$ Straw or $30.2 \%$ Sawdust can meet infiltration requires of rainwater whose rainstorm recurrence period is 10 years. The clay is not suitable for urban green space soils with higher rainwater storage and infiltration requirements. The reformed green space can effectively reduce the runoff peak flow and delay the generated time of the runoff. The higher the content of the modifier, the more obvious the advantage of promoting the hydrological cycle and reducing the runoff.
\end{abstract}

\section{Introduction}

As a natural rainwater storage and purification facility, urban green space not only helps enhance the infiltration of runoff to supplements the groundwater ${ }^{[1-3]}$, but also reduces the speed of runoff. Besides, it can improve the removal efficiency of pollutants settlement and reduce the scour of soils by runoff $f^{[4-5]}$. Urban green space also plays a very important role in reducing the runoff peak flow $^{[6-8]}$. The opinion of the State Council of the People's Republic of China on strengthening urban infrastructure construction emphasizes that it is very necessary to increase the ability of urban green spaces to gather runoff, replenish groundwater and purify ecology ${ }^{[9]}$.

The function of urban green space to promote runoff circulation is achieved through soil infiltration. In cities such as Shanghai and Guangzhou, and even in some cities where there is not sufficient runoff, flooding caused by the ponding after heavy rain occurred. This is not only due to the fact that the design of the municipal drainage network is lagging behind, but also has something to do with that the urban green space have not really played a role in enhancing the infiltration of runoff. According to reports of urban green space, 37 percent of the urban green space soil in Nanjing whose infiltration rate is less than $0.333 \mathrm{~mm} / \mathrm{min}$ is slow infiltration levels. ${ }^{[10]}$ The average infiltration rate of the urban green space soil in Shanghai Chenshan Botanical Garden is only $0.059 \mathrm{~mm} / \mathrm{min}$ and some of the samples were even 0 $\mathrm{mm} / \mathrm{min}^{[11]} .78 .9$ percent of the urban green space soil in Heifei is belong to the medium and slow infiltration levels. In other words, it is only 21.1 percent of the urban green space soil in Heifei belong to the fast infiltration levels. It can be seen that the infiltration rate of the urban green space soil in China is generally low, which is mainly due to the low permeability coefficient. Therefore, it is very meaningful to use local conditioner to enhance the storage of runoff in urban green space.

\section{2 materials and basic characteristics}

Three different types of soil were selected for the test, which were taken from different regions in Yangzhou. The basic characteristics are shown in Table 1.

Table 1 the index of soil

\begin{tabular}{|c|c|c|c|c|c|}
\hline \multirow{2}{*}{ number } & \multicolumn{3}{|c|}{ Particle composition \% } & \multirow{2}{*}{$\begin{array}{l}\text { unit weight } \\
\mathrm{g} \cdot \mathrm{cm}^{-3}\end{array}$} & \multirow{2}{*}{$\begin{array}{l}\text { The type } \\
\text { of soil }\end{array}$} \\
\hline & sand & silt & clay & & \\
\hline
\end{tabular}

First Author: Lou keke, 1kk_mail@163.com, Corresponding author: Wu zhengguang, male, Jiangsu, Professor (472761807@qq.com), mainly engaged in road works. 


\begin{tabular}{llllll}
\hline 1 & 95.1 & 3 & 1.9 & 1.22 & sandy soil \\
2 & 40.4 & 38.3 & 21.3 & 1.30 & loam \\
3 & 10 & 50 & 40 & 1.65 & Clay soil \\
\hline
\end{tabular}

The straw and sawdust were chosen to be the conditioner, which are light, loose large porosity so that they have can increase the permeability and water retention.In addition, they have wide sources and low prices. These show that the straw and sawdust are ideal materials to be as the conditioner. Its physical properties are shown in Table 2.

Table 2 the physical properties of the conditioner

\begin{tabular}{lll}
\hline the physical properties & straw & sawdust \\
\hline unit weight $\mathrm{kg} \cdot \mathrm{m}^{-3}$ & 192.4 & 230.1 \\
\hline
\end{tabular}

\section{Experiments}

\subsection{Preparation of soil samples}

Different types of soil samples and the conditioners were mixed for use. Taking into account the different types of soil permeability coefficient varies greatly, the following quantities of mix were determined by the results of preliminary experiments:

sandy soil: sandy soil $+5 \%$ 、10\%、15\%straw(sawdust); Loam: loam $+20 \%$ 、25\%、30\%straw(sawdust);

Clay soil: Clay soil $+20 \% 、 30 \%$ s、 $40 \%$ straw(sawdust).

\subsection{Soil column filling}

The different soil samples whose height is $20 \mathrm{~cm}$ were added to the soil column. After that, it needs to be compacted 3 times manually and 2 times hydraulically to ensure uniform compaction.

\subsection{Penetration test}

Firstly, the upper valve was opened to ensure the constant head. At the same time, the bottom valve was opened. Then, the penetration test can be started. When the outlet The outlet began to discharge water, the electronic balance at the outlet could be cleared and this time is recorded as $0 \mathrm{~min}$. The readings of electronic balance were recorded at time intervals of 5, 10, 20, 30, $45,65,90,120(140,160,180)$ minutes. Finally, the volume of water samples were calculate by quality. In combination with Darcy's law, the computational formula of permeability coefficient is shown as Formula 1:

$$
K=\frac{V \cdot L}{A \cdot \Delta h \cdot t}
$$

\section{Results and Discussion}

4.1 Effect of Types and Dosages of the conditioners on the soil samples' permeability coefficient
The rules of the permeability coefficient of the different soil samples that caused by types and dosages of the conditioners are shown as Figure.1.
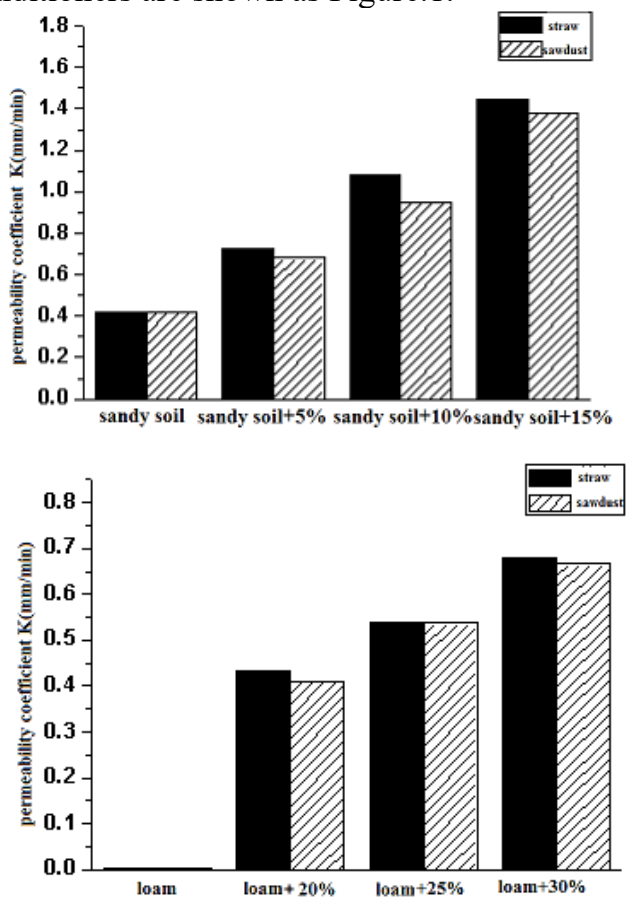

(a)

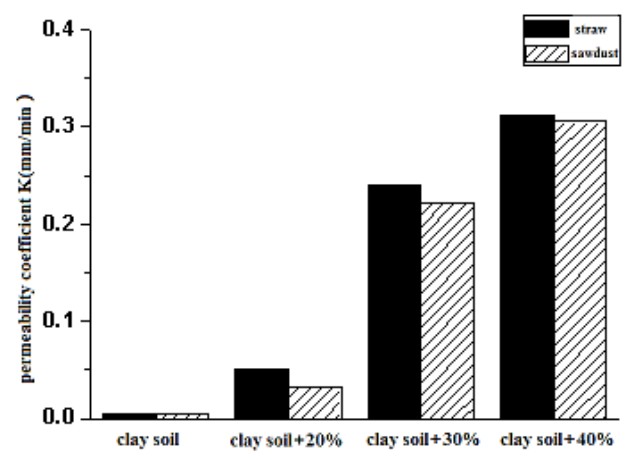

(b)

Figure.1 Relationship between permeability coefficient and types and dosages of the conditioners

As can be seen from Figure 1a-Figure 1c: Different types of soil have very different permeability coefficients. The stable infiltration rates of sand soil, loam and clay soil were $0.428 \mathrm{~mm} / \mathrm{min}, 0.00193 \times 10-3$ $\mathrm{mm} / \mathrm{min}$, and $0.000502 \mathrm{~mm} / \mathrm{min}$, respectively. The stable infiltration rates of sand soil with $5 \%, 10 \%$, and $15 \%$ of the conditioners is 1.7 times, 2.5 times, and 3.4 times of the original sand soil. The permeability coefficient of loam soil itself is small. After adding 20\%, 25\%, and $30 \%$ of the conditioners, the permeability coefficient can reach $0.434 \mathrm{~mm} / \mathrm{min}-0.666 \mathrm{~mm} / \mathrm{min}$, which increased 200-350 times of the original loam soil. The permeability coefficient of clay soil is very small. After adding $40 \%$ of sawdust, the permeability coefficient reached $0.306 \mathrm{~mm} / \mathrm{min}$, which is increased by three orders of magnitude. It can be seen that the addition of the conditioners can significantly increase the 
permeability coefficient. With the increase of the conditioners, the permeability coefficient is gradually improved. This is owing to the permeability of the soil improved by the conditioners. The greater the dosages of the conditioners, the more obvious the improvement of soil permeability.

Under the same conditions, straw improved slightly better than sawdust. This is because the unit weight of the straw is smaller. Under the same quality conditions, the volume of the straw is larger, which make the straw dispersed more densely in the soil and form more micropores. Based on the above results, the relationship between the permeability coefficient and the dosages of the conditioners is fitted as shown in Table 3, Where $\mathrm{K}$ is the permeability coefficient and $\mathrm{X}$ is the dosages of the conditioner.

Table 3 the fitted equation and correlation of permeability coefficient and the dosages of the conditioner

\begin{tabular}{cccc}
\hline $\begin{array}{c}\text { The type } \\
\text { of soil }\end{array}$ & $\begin{array}{c}\text { The type of } \\
\text { the } \\
\text { conditioner }\end{array}$ & the fitted equation & $\mathrm{R}^{2}$ \\
\hline sandy & straw & $\mathrm{K}=0.0679 \mathrm{X}+0.4087$ & 0.9978 \\
soil & sawdust & $\mathrm{K}=0.0627 \mathrm{X}+0.3903$ & 0.982 \\
& straw & $\mathrm{K}=0.0223 \mathrm{X}-0.003$ & 0.9979 \\
loam & sawdust & $\mathrm{K}=0.0218 \mathrm{X}-0.0054$ & 0.997 \\
& straw & $\mathrm{K}=0.081 \mathrm{X}-0.032$ & 0.8707 \\
Clay soil & sawdust & $\mathrm{K}=0.079 \mathrm{X}-0.0379$ & 0.8397 \\
\hline
\end{tabular}

As shown in Table 3, the fitting correlation between the straw and sawdust dosages and the permeability coefficients of sandy soil and loam were more than 0.98 , and the fitting correlation between the straw, sawdust dosages and clay permeability coefficient was also above 0.83. This showed that it has a good fitting correlation between the permeability coefficient and the dosages of the conditioners. This is mainly because the conditioners enriched the porosity of the soil, and the porosity is closely related to the dosages of the conditioners.

\subsection{Requires for permeability in different rainstorm recurrence period}

Taking Yangzhou as an example, a typical rainfall process was designed based on the Chicago flow process line model. A rainy peak coefficient of 0.4 and rain-fall time of 120 minutes was taken as an example. The computational formula of rainfall intensity in Yangzhou is shown as Formula $2^{[13]}$. The rules between rainfall intensity and rainfall duration are shown in Figure 2.

$$
q=\frac{8248.13(1+0.641 \lg P)}{(t+40.3)^{0.95}}
$$

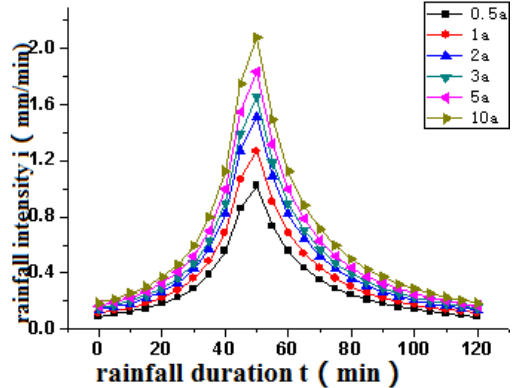

Figure 2 the rules between the rainfall intensity and the duration

The rainfall of the different rainstorm recurrence period are shown in Table 4.

Table 4 the rainfall of the different rainstorm recurrence period

\begin{tabular}{ccccccc}
\hline $\begin{array}{c}\text { recurrence } \\
\text { period a }\end{array}$ & 0.5 & 1 & 2 & 3 & 5 & 10 \\
\hline $\begin{array}{c}\text { Rainfall } \\
\mathrm{mm}\end{array}$ & 38.57 & 47.80 & 57.02 & 62.41 & 69.21 & 78.43 \\
\hline
\end{tabular}

The green space system can be considered as rainwater drainage systems whose infiltration capacity $\mathrm{W}_{\mathrm{p}}$ is shown as Formula 3.

$$
W_{P}=K \cdot J \cdot A_{s} \cdot t_{s}
$$

The form of formula (3) can be transformed to get formula (4):

$$
K=\frac{W_{\mathrm{p}}}{J \cdot A_{S} \cdot \mathrm{t}_{S}}
$$

Assuming that rainfall at different rainstorm recurrence period requires complete infiltration within the rainfall duration. The minimum permeability coefficient to meet the requirements at different rainstorm recurrence period can be seen in Table 5 .

Table 5 the minimum permeability coefficient at different rainstorm recurrence period

\begin{tabular}{ccccccc}
\hline $\begin{array}{c}\text { recurrence } \\
\text { period a }\end{array}$ & 0.5 & 1 & 2 & 3 & 5 & 10 \\
\hline $\begin{array}{c}\text { permeability } \\
\text { coefficient } \\
\text { mm.min }\end{array}$ & $\begin{array}{c}0.32 \\
1\end{array}$ & 0.398 & 0.475 & 0.520 & 0.577 & 0.654 \\
\hline
\end{tabular}

Combined with the previously the fitted equation, it can be seen that: for sandy soil, the soil reformed by $3.6 \%$ Straw or $4.2 \%$ Sawdust can meet infiltration requires of rainwater whose rainstorm recurrence period is 10 years. For loam, the soil reformed by $18 \%$ straw or $18.5 \%$ sawdust can meet infiltration requires of rainwater whose rainstorm recurrence period is 1 years. The loam reformed by $23.5 \%$ straw or $24.1 \%$ sawdust can meet infiltration requires of rainwater whose rainstorm recurrence period is 3 years. The loam reformed by $29.5 \%$ straw or $30.2 \%$ sawdust can meet infiltration requires of rainwater whose rainstorm recurrence period is 10 years. For clay soil, the soil reformed by $40 \%$ straw or sawdust can not meet infiltration requires of rainwater whose rainstorm recurrence period is 0.5 years. From the view of maintaining soil biodiversity and cost, the dosage of straw or sawdust should not continue to increase. So the clay is not suitable for urban green space soils with higher rainwater storage and infiltration requirements. 
The dosage of conditioner under different permeability

requirements are shown in Table 6.

Table 6 The dosages of the conditioner under different ermeability requirements

\begin{tabular}{|c|c|c|c|c|c|c|c|c|c|c|c|c|c|}
\hline \multicolumn{2}{|c|}{ recurrence period } & \multicolumn{2}{|c|}{0.5} & \multicolumn{2}{|c|}{1} & \multicolumn{2}{|c|}{2} & \multicolumn{2}{|c|}{3} & \multicolumn{2}{|c|}{5} & \multicolumn{2}{|c|}{10} \\
\hline \multicolumn{2}{|c|}{$\begin{array}{c}\text { permeability } \\
\text { coefficient } \mathrm{mm} \cdot \mathrm{min}^{-1}\end{array}$} & \multicolumn{2}{|c|}{0.321} & \multicolumn{2}{|c|}{0.398} & \multicolumn{2}{|c|}{0.475} & \multicolumn{2}{|c|}{0.520} & \multicolumn{2}{|c|}{0.577} & \multicolumn{2}{|c|}{0.654} \\
\hline \multirow{4}{*}{$\begin{array}{c}\text { The } \\
\text { dosages of } \\
\text { the } \\
\text { conditioner } \\
\%\end{array}$} & & straw & $\begin{array}{l}\text { saw } \\
\text { dust }\end{array}$ & straw & $\begin{array}{c}\text { sawd } \\
\text { ust }\end{array}$ & straw & $\begin{array}{l}\text { sawd } \\
\text { ust }\end{array}$ & straw & $\begin{array}{l}\text { sawd } \\
\text { ust }\end{array}$ & straw & $\begin{array}{l}\text { sawd } \\
\text { ust }\end{array}$ & straw & $\begin{array}{l}\text { sawd } \\
\text { ust }\end{array}$ \\
\hline & $\begin{array}{l}\text { sandy } \\
\text { soil }\end{array}$ & 0 & 0 & 0 & 0 & 1 & 1.4 & 1.6 & 2 & 2.5 & 3 & 3.6 & 4.2 \\
\hline & loam & 14.5 & 15 & 18 & 18.5 & 21.4 & 22 & 23.5 & 24.1 & 26 & 26.7 & 29.5 & 30.2 \\
\hline & $\begin{array}{l}\text { Clay } \\
\text { soil } \\
\end{array}$ & - & - & - & - & - & - & - & - & - & - & - & - \\
\hline
\end{tabular}

\subsection{Effect on soil rainwater Storage Capacity before and After Improvement}

In order to study the impact of green space soils before and after improvement on rainwater infiltration and peak flow reduction. The rainstorm recurrence period in Yangzhou was taken as an example.

The calculation of the runoff discharge and the peak reduction during the rainfall whose rainstorm recurrence period is 2 years, 3 years, 5 years, and 10 years. A green land with an area of 1ha was taken as an example for calculation, where the low elevation greenbelt area accounts for $10 \%$ and the concave depth is $100 \mathrm{~mm}$. The original sandy soil, sandy soil reformed by $5 \%$ straw and sandy soil reformed by $10 \%$ straw were compared to analyse the impact of green space soils before and after improvement on rainwater infiltration and peak flow reduction.
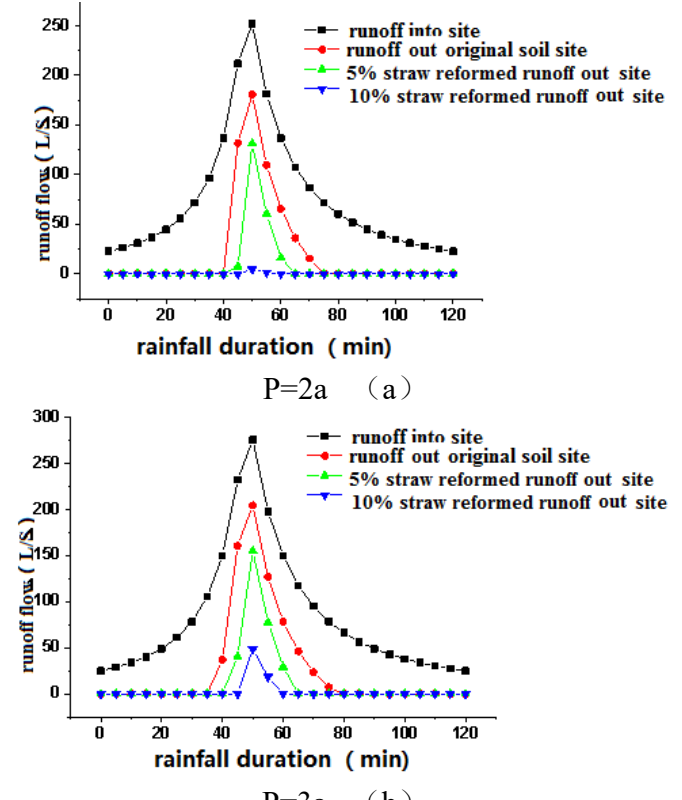

$\mathrm{P}=3 \mathrm{a} \quad(\mathrm{b})$
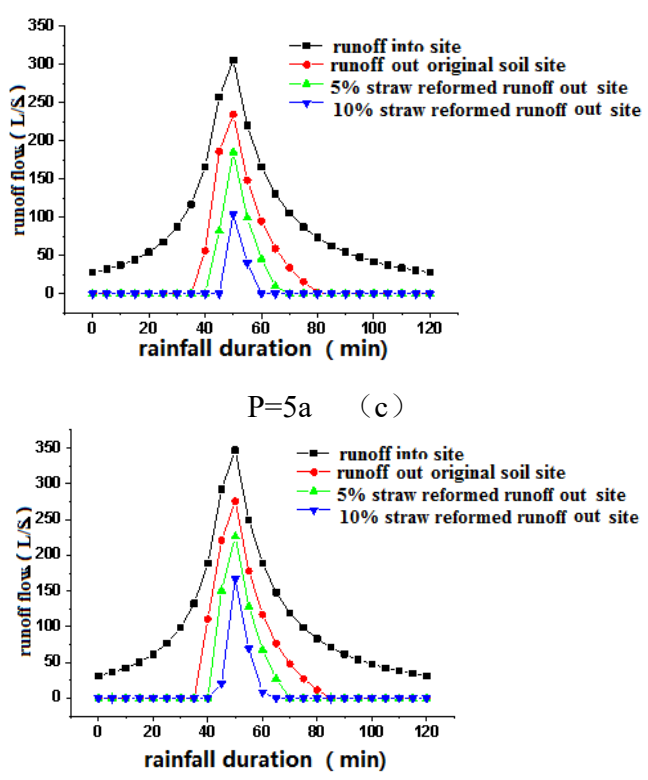

$\mathrm{P}=10 \mathrm{a} \quad(\mathrm{d})$

Figure 3 the rues between runoff flow and duration under different recurrence period

Through the analysis of Figures $3 a-3 d$, it was found that compared with the original soil, the soil reformed by $5 \%$ straw could increase the peak flow reduction by $27 \%$, $24 \%, 21 \%, 18 \%$ under the recurrence period of $2 \mathrm{a}, 3 \mathrm{a}, 5 \mathrm{a}$, and $10 \mathrm{a}$. The soil reformed by $10 \%$ straw could increase the peak flow reduction by $97 \%$ 、 $76 \%$ 、 $56 \%$ 、 $40 \%$ under the recurrence period of $2 \mathrm{a}, 3 \mathrm{a}, 5 \mathrm{a}$, and $10 \mathrm{a}$. It can be seen that the green space system has the capacity of seepage for runoff under different recurrence period. It can effectively reduce the runoff peak flow and delay the generated time of the runoff. The improved soil has more advantages than the original soil in terms of rainwater infiltration. The larger the amount, the greater the advantage. The higher the content of the modifier, the greater the advantage. When the recurrence period is 2 years, the green space soil refromed with $10 \%$ straw will not generate runoff. Even if the recurrence period is 5 years or 10 years, the improved soil has the effect of significantly reducing peak flow of runoff.

\section{Conclusion}

The mix of soil and straw and sawdust can greatly enrich the porosity of the soil. Through adding the different 
types and dosages of conditioners, the rules of different kinds of soil permeability and the effects on runoff $r$ seepage were studied. The following conclusions were obtained:

(1) straw and sawdust are both superior conditioners that effectively increase the permeability coefficient of soil. According to the comparison under the same conditions, the improvement effects of straw is slightly better than sawdust, but no order of magnitude difference.

(2) it has a good fitting correlation between the permeability coefficient and the dosages of the conditioners. for sandy soil, the soil reformed by $3.6 \%$ Straw or $4.2 \%$ Sawdust can meet infiltration requires of rainwater whose rainstorm recurrence period is 10 years. For loam, the soil reformed by $18 \%$ straw or $18.5 \%$ sawdust can meet infiltration requires of rainwater whose rainstorm recurrence period is 1 years. The loam reformed by $23.5 \%$ straw or $24.1 \%$ sawdust can meet infiltration requires of rainwater whose rainstorm recurrence period is 3 years. The loam reformed by $29.5 \%$ straw or $30.2 \%$ sawdust can meet infiltration requires of rainwater whose rainstorm recurrence period is 10 years. For clay soil, it is not suitable for urban green space soils with higher rainwater storage and infiltration requirements.

(3) The reformed green space can effectively reduce the runoff peak flow and delay the generated time of the runoff. The higher the content of the modifier, the more obvious the advantage of promoting the hydrological cycle and reducing the runoff.

\section{Acknowledgment}

Fund Project: National Natural Science Foundation of China ( 51578481 ) ; Jiangsu Postgraduate Innovation Project (KYCX17_1880)

\section{References}

1. Ling $\mathrm{H} \mathrm{R}$, Wang $\mathrm{W}$, Fan $\mathrm{Z} \mathrm{Q}$, Wang $\mathrm{X}$ R. Ecological effect of green space of Shanghai in different spatial scales in past 20 years. Acta Ecologica Sinica, 2011, 31(19) : 5607-5615.

2. Ramesh Anguluri,Priya Narayanan. Role of green space in urban planning: Outlook towards smart cities[J]. Urban Forestry \&amp; Urban Greening,2017,25.

3. Abdullah Akpinar. How is quality of urban green spaces associated with physical activity and healthy[J]. Urban Forestry \&amp; Urban Greening,2016,16:

4. Jian-sheng WU, Menglin SI, Wei-feng LI. Spatial equity analysis of urban green space from the perspective of balance between supply and demand: A case study of Futian District, Shenzhen, China. Chinese Journal of Applied Ecology, 2016, 27( 9) : 2831-2838

5. M. Dennis,P. James. Site-specific factors in the production of local urban ecosystem services: A case study of community-managed green space. Ecosystem Services,2016,17.

6. Märit Jansson,Elin Sundevall,Mark Wales. The role of green spaces and their management in a childfriendly urban village $[\mathrm{J}]$. Urban Forestry \&amp; Urban Greening,2016.

7. Kshama Gupta,Arijit Roy,Kanishka Luthra,Sandeep Maithani,Mahavir. GIS based analysis for assessing the accessibility at hierarchical levels of urban green spaces. Urban Forestry \&amp; Urban Greening,2016,:.

8. Rixt A. Bijker,Frans J. Sijtsma. A portfolio of natural places: Using a participatory GIS tool to compare the appreciation and use of green spaces inside and outside urban areas by urban residents. Landscape and Urban Planning,2016.

9. 《State Council's Opinions on Strengthening Urban Infrastructure Construction 》 ( ( 2013) 36. Standard life,2017,(01):60-61.

10. Jin-ling YANG, Gan-lin ZHANG, Da-gang YUAN. Characteristics of wateri nfiltration in urban soils of Nanjing City. Chinese Journal of Applied Ecology, 2008, 19(2): 363-368.

11. Xi WEI, Ningyuan TANG, Tian LI. Field Survey and Improvement for Soil Infiltration Characteristics of Urban Green Land in Shanghai. Water Purification Technology, 2011, 30(4): 78-83.

12. Wei Junling, Jin Youqian, Gao Hongjian, Chang Jiang, $\mathrm{Xu}$ Wei. Investigation on Soil Water Infiltration in Different Urban Green Lands in Hefei City. Chinese Agricultural Science Bulletin, 2012, 28(25): 302-307.

13. Ruizhi Qian. The Estimation of Parameters of Rainstorm Intensity Formula in Short Duration in Yangzhou City. Jiangsu Water Resources, 2013,(3):40-41. 